\title{
Mclaughlin Procedure Treatment of Bilateral Sequential Posterior Dislocation Fracture of the Shoulder: A Case Report"
}

'Bilateral Ardışık Omuz Kırıkıı Çıkığının Mclaughlin

Prosedürü ile Tedavisi: Olgu Sunumu

\section{Gökhan Bülent Sever', Mehmet Cenk Cankuş', Faruk Aykanat', Mehmer Dokur²,} Zekiye İpek Katırcı Kırmaci ${ }^{3}$

' Department of Orthopedics and Traumatology, Sanko University School of Medicine, Gaziantep, Turkey.

${ }^{2}$ Department of Emergency Medicine, Biruni University School of Medicine, Istanbul, Turkey

${ }^{3}$ Department of Physiotherapy and Rehabilitation, Sanko University, Faculty of Health Sciences, Gaziantep, Turkey

Yazışma Adresi / Correspondence: Gökhan Bülent Sever

Department of Orthopedics and Traumatology, Sanko University School of Medicine, Gaziantep, Turkey. T: +90342 2116500 E-mail: gokhansever@hotmail.com

Geliş Tarihi / Received : 25.02.2018 Kabul Tarihi / Accepted : 28.03.2018

\footnotetext{
Abstract

Posterior dislocation of the shoulder is extremely rare condition. Common etiologic causes are extreme trauma, epilepsy and electroconvulsive therapy. Most cases are misdiagnosed due to inappropriate phisical examination and/or inadequate radiologic evaluation. In the literature several operation technics are described. Here we present a case with posterior dislocation of left shoulder after succesful treatment of right shoulder. ( Sakarya Med J, 2018, 8(2):447-452 )

Keywords Glenohumeral dislocation; humeral fractures, proximal; Mclaughlin procedure

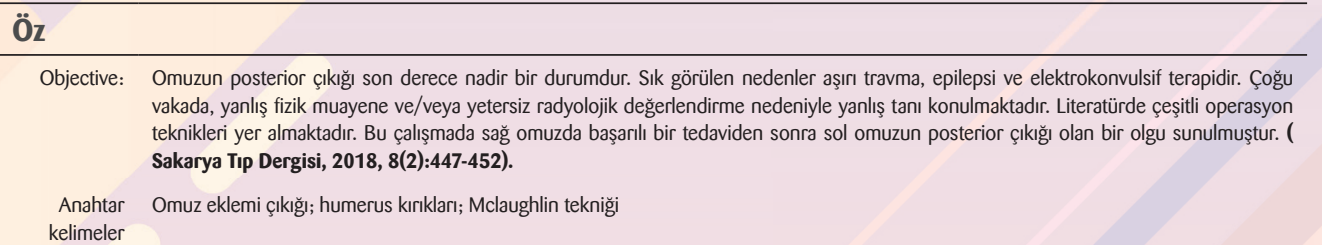




\section{Introduction}

PSD (posterior shoulder dislocation) is a rare injury. It accounts for a small percentage of dislocations occuring in the general population between 1,7 and 4,3\%. ${ }^{1}$ Most of the cases due to epileptic seizures. ${ }^{2}$ Unfortunately most of the cases were misdiagnosed in initial evaluation. Because on anteroposterior $\mathrm{X}$-Ray it could be easily misdiagnosed.

Management of the treatment can be surgical or non-surgical. According to several factors the treatment strategy is being determined. Several surgical technics have been described. Reconstruction of the humeral head with bone grafts, medial transfer of the subscapularis tendon into the bone defect, and anatomical shoulder replacement. ${ }^{3-8}$

\section{Case}

32-year-old male patient with known epilepsy history admitted to the hospital because of right shoulder pain on 2010. His shoulder pain was started after epileptyc seizure and continued about 30 days. On his physical examination right shoulder external rotation was decreased. Anteroposterior $\mathrm{X}$-Ray views were carried out which showed right posterior locked fracture dislocation of the humeral head. computed tomography (CT) evaluation of the shoulder showed $\% 30$ humeral head defect reverse Hill-Sachs lesion (Mclaughlin lesion) (Figure 1A).

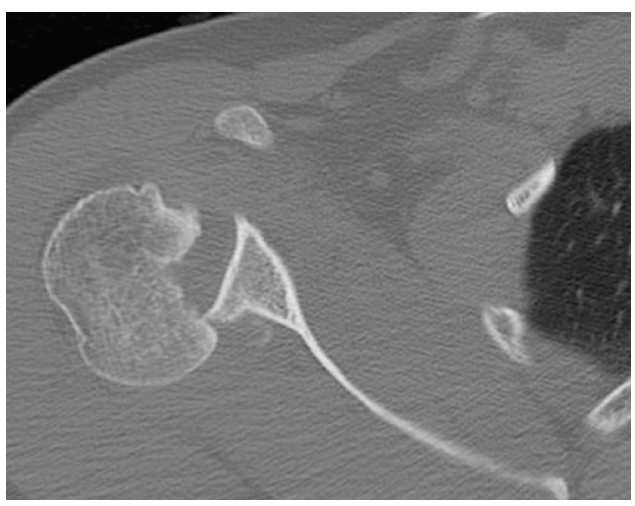

Figure 1A. Right shoulder pre-operation Computed Tomography view

The patients right shoulder was treated according to Mclaughlin procedure. After operation Spica was used 3 weeks. Then active-assisted and active range of motion and rotator cuff strenghteninig exercises were started. In his routine follow-up at third month his shoulder range of motion was normal (Figure 1B).

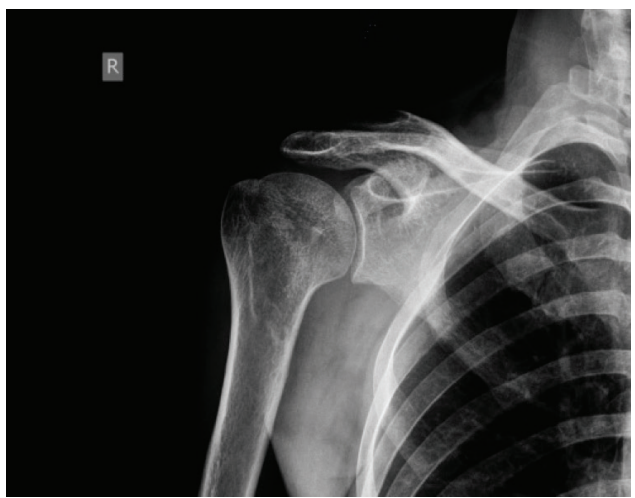

Figure 1B. Right shoulder post-operation Anteroposterior X-Ray 
7 years later the patient admitted to orthopedia department because of left shoulder pain and decreased left shoulder external rotation after epileptyc seizure. X-ray of the shoulder AP view were conducted which showed left posterior locked fracture dislocation of the humeral head (Figure $2 A)$.

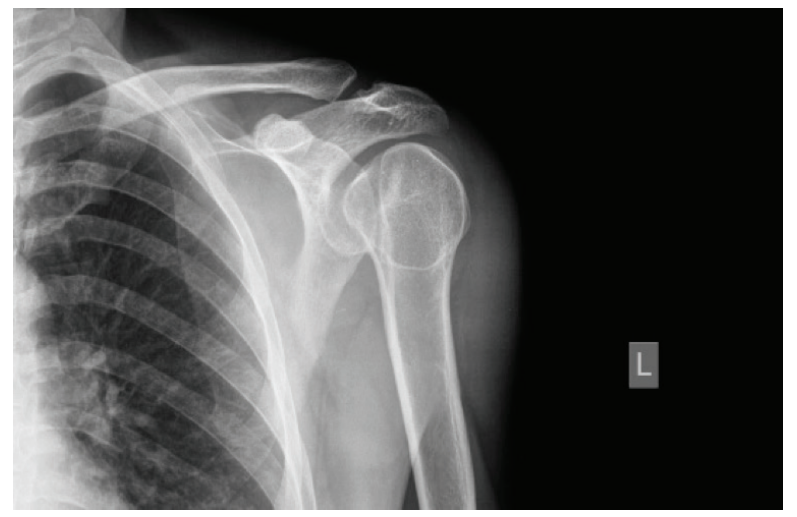

Figure 2A. Left shoulder pre-operation Anteroposterior X-Ray

MRI showed a \%35 humeral head defect reverse Hill-Sachs lesions (Figure 2B). Left shoulder Mclaughlin procedure was done and shoulder Spica in external rotation followed by passive, then active-assisted, and active range of motion and rotator cuff strengthening exercises were started (Figure 2C). Prior to the commencement of the study,this research carried out on humans has been in compliance with the Helsinki Declaration, adopted by the 18th World Medical Assembly, Helsinki, Finland, June 1964 and all participant signed an informed consent form prior to participation.

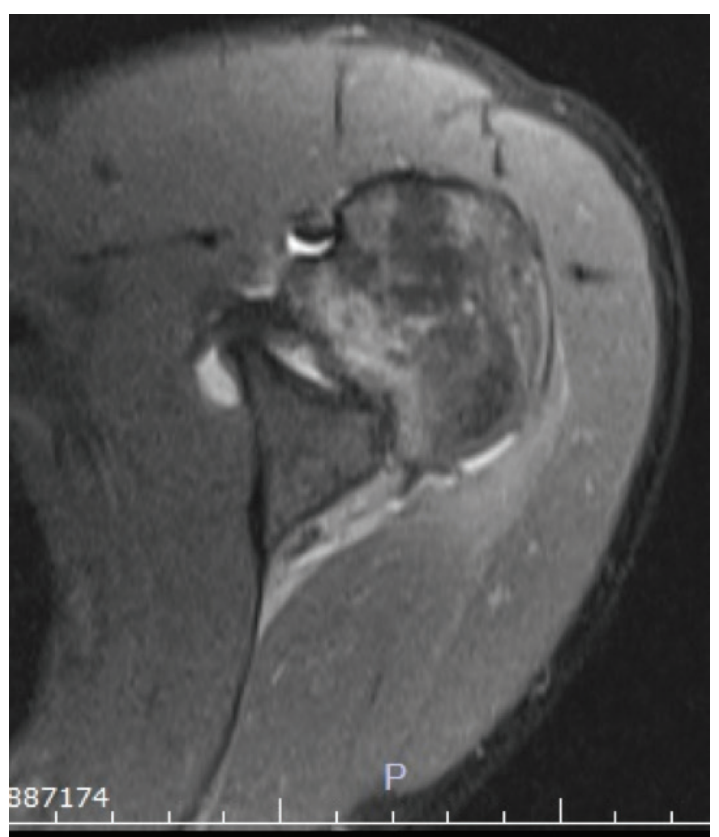

Figure 2B. Left shoulder pre-operation Magnetic Resonance Imaging view
Sakarya Med J $2018 ; 8(2): 447-452$

SEVER et al. Mclaughlin Procedure in Posterior Dislocation Fracture of the Shoulder 


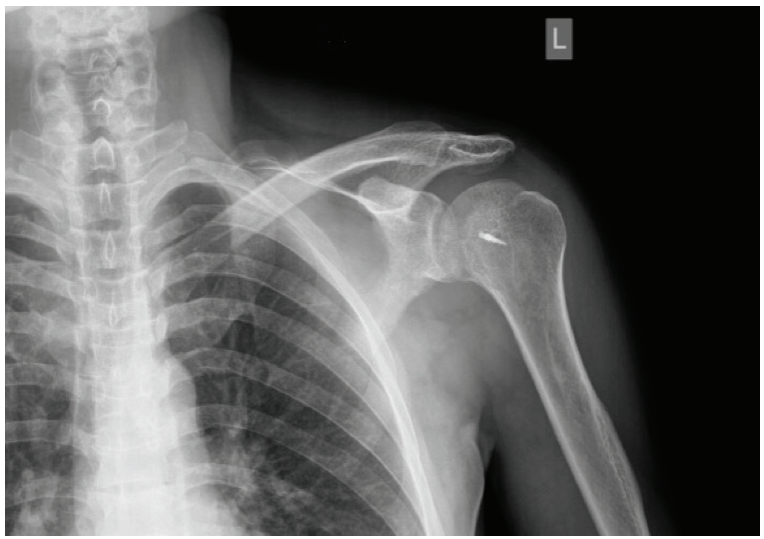

Figure 2C. Left-shoulder post-operation Anteroposterior X-Ray

\section{Discussion}

Posterior shoulder dislocation (PSD) is a rare injury. It is accounting for only $2-5 \%$ of all shoulder dislocations.9 Acoording to Neer and Foster PSD with shoulder fracture less frequent: 0,9\% of 1500 shoulder fracture-dislocations. ${ }^{10}$ While bilateral PSD are rarer still: 0,6 cases among a population of 100.000 people per year. ${ }^{11}$

Although most of the cases caused by epileptyc seizures; electrocution and extreme trauma (known as triple $\mathrm{E}$ syndrome) are the other causes of fracture dislocation of shoulder. ${ }^{12}$ During a seizure proposed mechanism of shoulder injury is well described. ${ }^{11}$ PSDs usually ocur following unbalanced forceful muscle contractions.

Unfortunately up to $50 \%$ of cases are misdiagnosed on initial evaluation. 13 PSD can easily be misdiagnosed on the AP x-ray so lateral (axillary) view should be obtained. CT or magnetic resonance imaging (MRI) is performed before management to decide the surgical approach. Early detection could be the key for an appropriate treatment.

The common complications of PSD are avascular necrosis of the humearl head, secondary osteoarthritisand impaired range of movement. ${ }^{14}$

Management of PSD depends on several factors such as the type of the fracture, severity of injury, whether bilateral or unilateral, acute or chronic (3 weeks or more), patient's age.

Kokkalis ZT. et al. are reported a treatment algorithm on August 2016. According to this algorithm surgical and nonsurgical technics are described. They proposed to decide the management according to factors as described above. ${ }^{15}$

In our patient after an epileptic seizure PSD was seen. In the right shoulder the diagnosis was delayed 4 weeks, and the patient was young. Then we performed Mclaughlin procedure. After 7 years patient attempted to the hospital because of left shoulder dislocation. In that time diagnosis was not delayed. We decide to perform Mclaughlin procedure, because MRI evaluation of the shoulder showed \%35 humeral head defect reverse Hill-Sachs lesion. 


\section{Conflict of interest:}

There is not any conflict of interest.

\section{Conclusion}

PSD can easily be misdiagnosed. Especially patients with history of extreme trauma, epileptic seizure or electrocution the diagnosis must be kept in mind. Appropriate radiologic evaluation must be done. Treatment options depends on several factors.
Sakarya Med J

$2018 ; 8(2): 447-452$

SEVER et al.

Mclaughlin Procedure in Posterior Dislocation

Fracture of the Shoulder 
1. Robinson CM, Akhtar A, Mitchell M, Beavis C. Complex posterior fracture-dislocationof the shoulder. Epidemiology, injury patterns, and results of operative treatment. Bone Joint Surg Am 2007;89:1454-66.

2. Bühler M, Gerber $C$. Shoulder instability related to epileptic seizures. J Shoulder Elbow Surg 2002;11:339-44.

3. Gerber C, Lambert SM. Allograft reconstruction of segmental defects of the humeral head for the treatment of chronic locked posterior dislocation of the shoulder. J Bone Joint Surg Am 1996;78:376-82.

4. Chalidis BE, Papadopoulos PP, Dimitriou CG. Reconstrution of a missed posterior locked shoulder fracture-dislocation with bone graft and lesser tuberosity transfer: a case report. J Med Case Rep 2008;2:260.

Sakarya Med 2018;8(2):447-452

SEVER et al.
5. Mclaughlin HL. Posterior dislocation of the shoulder. J Bone Joint Surg Am 1952;24:584-590.

6. Sperling JW, Pring M, Antuna SA, Cofield RH. Shoulder arthroplasty for locked posterior dislocation of the shoulder. J Shoulder Elbow Surg 2004;13:522-7.

7. Checchia SL, Santos PD, Miyazaki AN. Surgical treatment of acute and chronic posterior fracture-dislocation of the shoulder. J Shoulder Elbow Surg 1998; 7:53-65.

8. Pritchett JW, Clark JM. Prosthetic replacement for chronic unreduced dislocations of the shoulder. Clin Orthop Relat Res 1987;216:89-93.
9. Kowalsky MS, Levine WN. Traumatic posterior glenohumeral dislocation classification, pathoanatomy, diagnosis, and treatment. Orthop Clin N Am 2008;39:519-33.

10. Neer CS 2nd, Foster CR.Inferior capsular shift for involuntary inferior and multidirectional instability of the shoulder. A preliminary report. J Bone J Surg Am 1980;62:897-908.

11. Shaw JL. Bilateral posterior fracture dislocation of the shoulder and other traumas caused by convulsive seizures. J Bone Joint Surg Am 1971;53:1437-40.

12. Brackstone M, Patterson SD, Kertesz A. Triple E syndrome: bilateral locked posterior fracture dislocation of the shoulders. Neurology 2001;56:1403-4.

13. Clough TM, Bale RS. Bilateral posterior shoulder dislocation: the importance of the axillary radiographic view. Eur J Emerg Med 2001;8:161-3.

14. Pushpakumara J, Sivathiran S, Roshan L, Gunatilake S. Bilateral posterio fracture-dislocation of the shoulders following epileptic seizures: a case report and review of the literature. BMC Res Notes 2015;8:704-9.

15. Kokkalis ZT, lliopoulos ID, Antoniou G, Antoniadou T, Mavrogenis AF, Panagiotopoulos E. Posterior shoulder fracture-dislocation: an update with treatment algorithm. Eur J Orthop Surg Traumatol 2017;27:285-94. 